J. Environ. Sci.

Institute of Environmental Studies and Research - Ain Shams University

\title{
CORNCOB DRIVEN BIOCHAR FOR ADSORPTION OF WATER POLLUTANTS
}

\author{
Saleh, Rasha, M. ${ }^{(1)}$; Hewehy, M. A. ${ }^{(1)}$; El-Kady, M. Y. ${ }^{(2)}$; \\ Khalil, M. H. ${ }^{(2)}$ and Ali, M. E. M. ${ }^{(3)}$
}

1) Department of Basic Sciences, Institute of Environmental Studies and Research, Ain Shams University 2) Department of Chemistry- Faculty of Science, Ain Shams University 3) Water Pollution Research Department, National Research Center

\begin{abstract}
In this work, corncob waste was used as a solid adsorbent for removal of $\mathrm{Pb}, \mathrm{Ni}, \mathrm{Zn}, \mathrm{Cd}$ ions from aquatic ecosystem through batch techniques. The influences of bio-sorbent dose, $\mathrm{pH}$, concentration of metal ions and contact time with biochar on these heavy metal ions removal percentages were investigated. Optimum removal of $\mathrm{Pb}, \mathrm{Ni}, \mathrm{Zn}$ and $\mathrm{Cd}$ ions was achieved at bio-sorbent dose $(3 \mathrm{~g})$, and contact time (90 min.). Desorption experiments were performed due to the importance for the financial competitiveness of biosorption with other process, indicating that $(2.5 \mathrm{M})$ sodium hydroxide is the most promising desorbing agent for efficient sorbent regeneration. The results of this study confirm that corncob waste can be beneficially used for treating aquatic ecosystem containing $\mathrm{Pb}, \mathrm{Ni}, \mathrm{Zn}$ and $\mathrm{Cd}$ ions.
\end{abstract}

Key words: Adsorption, Biochar, Water pollutants, Biosorbent.

\section{INTRODUCTION}

With the rapid development of industrial activities, a large amount of industrial effluents containing heavy metals are released into surface and underground water, which resulted in a number of environmental problems (Barakat, 2011). Heavy metals such as lead, copper, and cadmium are toxic and non-biodegradable. They can accumulate in living organisms. and may thus pose a threat to human health (Kumar et al., 2014). Therefore, it is very 
important to develop effective technologies to treat heavy metal polluted wastewater before their discharge into natural environment. Although advanced water treatment technologies provide many good solutions to remove heavy metals, most of them may be associated with high operating cost and/or sludge disposal problems (Fu and Wang, 2011). Adsorption is considered a cost-effective choice for heavy metal removal from wastewater, especially at medium or low ion concentrations because it is economical, easy to handle and highly efficient (Hu et al., 2015; Inyang et al., 2012). Many studies have suggested bio-sorbents derived from waste biomass such as agricultural residues as a promising alternative agents for the treatment of heavy metals while reducing both preparation and running costs (Demirbas, 2008; Zhou et al., 2014).

Biochar, a pyrogenic carbon material derived from biomass, is one of the biosorbents that has received increased attention recently because of its strong affinity for various contaminants in water (Wang et al., 2015b; Yao et al., 2012; Zhou et al., 2014).

Biochars produced from waste biomass such as agricultural and forestry residues have shown good sorption ability to a variety of heavy metal ions in aqueous solutions (Ahmad et al., 2014; Mohan et al., 2014). Recently, techniques have been developed to produce engineered biochars with enhanced sorption ability to heavy metals, as well as, other contaminants in water.

In this work, we performed treatment of wastewater from inorganic pollutants. An adsorption technique was used for this treatment. Preparation a suitable adsorbent for decontamination of wastewater is one of aims of this 2 
work. We removed $\mathrm{Pb}, \mathrm{Zn}, \mathrm{Ni}$ and $\mathrm{Cd}$ ions as an example of inorganic pollutants.

\section{MATERIAL AND METHODS}

Biochar was prepared through direct pyrolysis of corn cob to be used for the removal of heavy metals from water. A range of experiments were conducted to evaluate the sorption ability of the biochar to $\mathrm{Pb}, \mathrm{Zn}, \mathrm{Ni}$ and $\mathrm{Cd}$ ions in aqueous solutions. The steps of this work were as follows:

(1) preparation and characterization of biochar; (2) assessment of the adsorption ability of the biochar to lead, Zinc, Nickel and cadmium; and (3) determination of the effects of contact time, $\mathrm{pH}$, concentration of metal ions and sorbent dosage, on the adsorption of the heavy metal ions onto the biochar.

Reagents and apparatus: Single component stock solutions of $1000 \mathrm{mg} / \mathrm{L}$ of metal ions were prepared by dissolving appropriate amounts of $1.57 \mathrm{~g}$ lead acetate, $2.77 \mathrm{~g}$ zinc nitrate, $1.69 \mathrm{~g}$ cadmium chloride, and $2.21 \mathrm{~g}$ nickel chloride in deionized water. The solutions were acidified with small amount of nitric acid. These chemicals were supplied by Sigma-Aldrich (Germany) and used without further purification. Dilution was used for preparation the required concentrations for the various steps of the investigation. Hydrochloric acid $\mathrm{HCl}$ (Merck) 1\% (V/V) and/or sodium hydroxide $\mathrm{NaOH}$ (Merck) were used for $\mathrm{pH}$ adjustment of the synthetic wastewater. A WTW digital $\mathrm{pH}$ meter model "525" (Germany) was used for the $\mathrm{pH}$ adjustment. Shaker (Stuart, UK) was also used for mixing the samples with sorbent. 
Preparation of biochar: Corncob were obtained from the cones were washed thoroughly with distilled water to remove impurities such as sand and leaves. The washed cones were then dried at $70{ }^{\circ} \mathrm{C}$ for $24 \mathrm{hrs}$ in an oven.

The scales on the dried cones were then removed and ground in a crusher. The resultant ground material powders were passed through British Standard Sieves (BSS) of $150 \mu \mathrm{m}$, and amount of corncob was weighed then they were crushed to small particles, the carbonization process was performed in muffle oven at $500{ }^{\circ} \mathrm{C}$ with $5{ }^{\circ} \mathrm{C} / \mathrm{min}$ for 2 hours in semi- closed system. After that, the carbonized materials were washed with $0.1 \mathrm{~N} \mathrm{HCl}$ and distilled water, until the $\mathrm{pH}$ of water become from 6.8 to 7 . Then it was dried in oven at $105^{\circ} \mathrm{c}$ over night. Then it was collected in an airtight plastic container and used for analysis, as well as, for adsorption experiments.

All plastic sample bottles and glassware were cleaned, then rinsed with deionized water and dried at $60^{\circ} \mathrm{C}$ in a temperature controlled oven. Adsorption procedure: Adsorption measurements were determined by batch experiments of known amount of the sample with $50 \mathrm{~mL}$ of aqueous adsorbate solutions as per in a series of $100 \mathrm{ml}$ glass bottles. The mixtures were shaken in a constant temperature orbital shaker at $250 \mathrm{rpm}$ at $30 \mathrm{oC}$ for a given time and then the suspensions were filtered through a whatman glass micro filter and the filtrates were analyzed using inductive coupled plasma optical emission spectroscopy instrument (ICP-OES) model (Agilent 5000 series). The experiments were carried out by varying the $\mathrm{pH}$ value of wastewater, contact time, and the amount of adsorbent. The removal efficiency was calculated based on the following equation Eq.: 


$$
\begin{aligned}
& \text { Removal efficiency } \\
& \quad=\frac{\mathrm{C}_{0}-\mathrm{C}_{t}}{\mathrm{C}_{0}} \times 100
\end{aligned}
$$

Where $\mathrm{C}_{0}(\mathrm{mg} / \mathrm{L})$ and $\mathrm{C}_{\mathrm{t}}(\mathrm{mg} / \mathrm{L})$ are the concentrations in the solution at time $\mathrm{t}=0$ and at time $\mathrm{t}$.

The kinetics of adsorption was carried out at low and high initial metal ion concentrations and at different $\mathrm{pHs}$ using the same adsorption procedure stated above. The only difference was that samples were collected and analyzed at regular time intervals during adsorption process.

Effect of pH and dose of biochar: Single component solutions of $\mathrm{Cd}$ (II), $\mathrm{Ni}$ (II), $\mathrm{Pb}$ (II), and $\mathrm{Zn}$ (II) with initial concentration $50 \mathrm{mg} / \mathrm{L}, 2.0 \mathrm{~g} / \mathrm{L}$ of biochar dose, $250 \mathrm{rpm}$ speed, $90 \mathrm{~min}$ contact time and $\mathrm{pH}$ ranging from 3 to 6.5 , the removal efficiency of metal ions using different dose of biochar was estimated for initial metal ion concentration of $50 \mathrm{ppm}(\mathrm{mg} / \mathrm{l})$ at $(0.25-3 \mathrm{~g} / \mathrm{l})$ respectively.

Effect of contact time and concentration of metal ions: To determine the required time for obtaining equilibrium, single component solutions of $\mathrm{Cd}$ (II), $\mathrm{Ni}$ (II), $\mathrm{Pb}$ (II), and $\mathrm{Zn}$ (II) with initial concentration $50 \mathrm{mg} / \mathrm{L}$ mixed at $250 \mathrm{rpm}$ with $2.0 \mathrm{~g} / \mathrm{L}$ of biochar for interaction at $\mathrm{pH}$ 6.5.

Single component solutions of different metal ions with different concentrations of 50,75, 100 and $200 \mathrm{mg} / \mathrm{L}$ were mixed at $200 \mathrm{rpm}$ with 2 $\mathrm{g} / \mathrm{L}$ of biochar for equilibrium time $90 \mathrm{~min}$ at $\mathrm{pH} 6.5$.

Point of zero charge (PZC): The point of zero charge (PZC) of the prepared biochar was determined by using $0.01 \mathrm{~mol} / \mathrm{L} \mathrm{NaCl}$ solutions, at $298 \mathrm{~K}$. Given volumes $(50 \mathrm{~mL})$ of $0.01 \mathrm{~mol} / \mathrm{L} \mathrm{NaCl}$ solution were taken and mixed with 50 $\mathrm{mg}$ of biochar, in different beakers. The $\mathrm{pH}$ values of the solutions were 
adjusted to 2, 4, 6, 8, 10and 12 using $\mathrm{HCl}$ or $\mathrm{NaOH}$ solutions. The initial $\mathrm{pH}$ of the solutions was recorded and each flask was covered with parafilm and shaken for $24 \mathrm{~h}$. The PZC value is found at different of $\mathrm{pH}$ zero.

\section{RESULTS AND DISCUSSION}

$\mathrm{pH}$ plays a very important role in the sorption of heavy metals, since it affects the surface charge of the adsorbent and the metal species present in the solution. The influence of the initial pH of Cd (II), Ni (II), $\mathrm{Pb}$ (II), and $\mathrm{Zn}$ (II) solutions on the removal efficiency has been evaluated under the following conditions. Fig 1. Represents the removal efficiency of $\mathrm{Cd}$ (II), $\mathrm{Ni}$ (II), $\mathrm{Pb}$ (II), and Zn (II) at different pH's

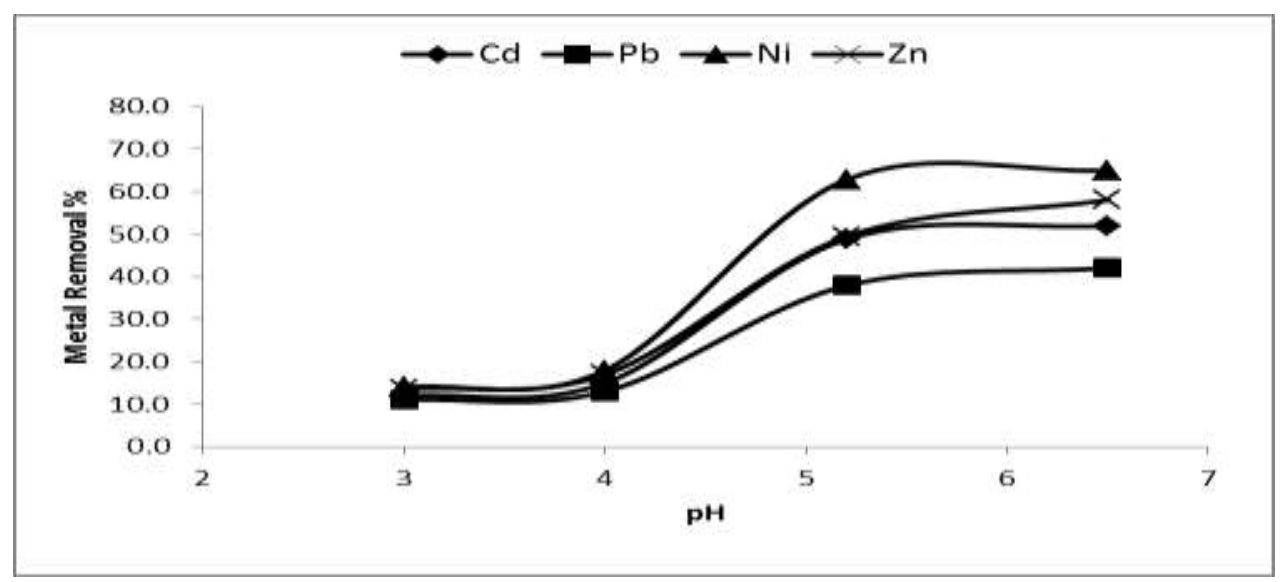

Fig. (1): Effect of $\mathrm{pH}$ on the removal efficiency of metal ions on biochar

Figure 1 revealed that there is an increase from $12 \%$ to $52 \% \%$ for $\mathrm{Cd}$ (II), $14 \%$ to $62 \%$ for $\mathrm{Ni}$ (II), $11 \%$ to $42 \%$ for $\mathrm{Pb}$ (II), and 13.5 to $58 \%$ for $\mathrm{Zn}$ (II). Notably, adsorption of Cd (II), Ni (II), Pb (II), and Zn (II) ions on biochar surface increased with increase in $\mathrm{pH}$ of solution. The point of zero charge of biochar is 5.7, so the surface of adsorbent will be positively charged 
at lower $\mathrm{pH}$ due to adsorption of hydrogen ions on the surface of adsorbents. At the same time, metals will be positively charged so it is hardly adsorbed at lower $\mathrm{pH}$. Meanwhile, at higher $\mathrm{pH}$ value, surface of biochar is negatively charged, and suitable for uptake the positively charged metals ions and consequently the removal efficiency is increased as well.

Fig. 2 represents a plot of the amount of zinc, cadmium, nickel and lead metal ion removal efficiency versus different dose of biochar for metal ion concentration of $50 \mathrm{mg} / \mathrm{l}$, respectively. Firstly, the adsorption rate of metal was enhanced with the biochar amount, whilst the more amount of biochar give a higher surface area and more active sites for adsorption. In case of adsorption of metals, the over amount of sorbent in the solution may lead to slight increase adsorption rate (ca: $8 \%$ ). This may be due to owe to agglomeration that diminishes the adsorption because active sites for adsorption are not completely occupied. From economic point of view, $2 \mathrm{~g} / \mathrm{L}$ is chosen as optimal dose for metals adsorption.

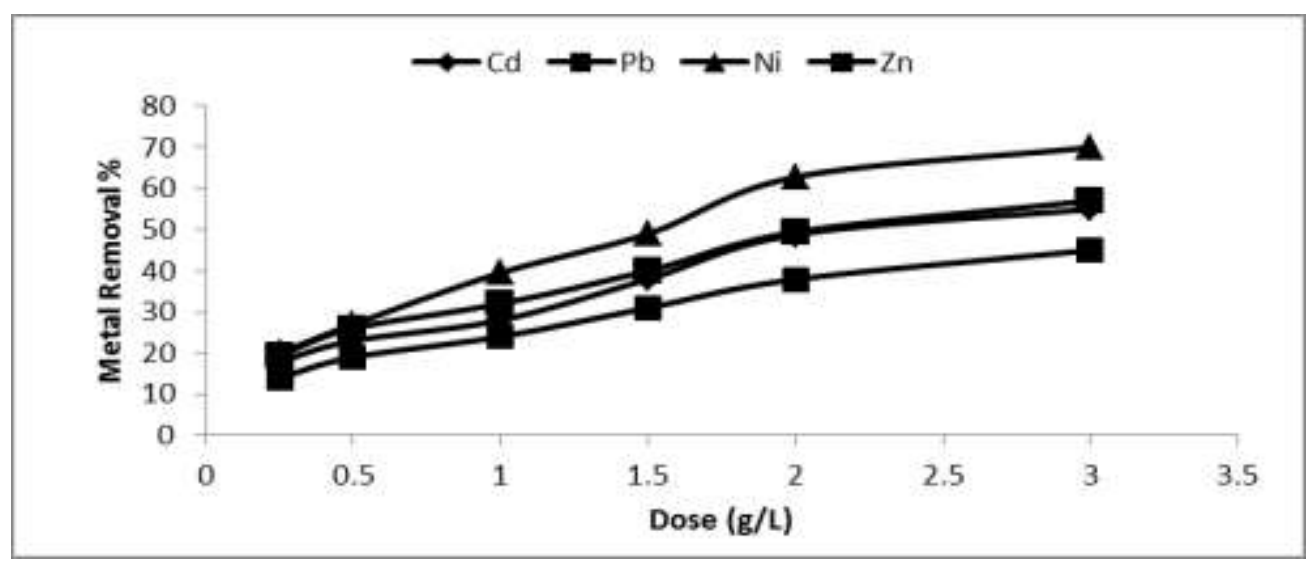

Fig. (2): Effect of adsorbent dose on the removal efficiency of metals ions on biochar 
The effect of contact time with adsorbent on the removal efficiency of $\mathrm{Cd}, \mathrm{Pb}, \mathrm{Ni}$ and $\mathrm{Zn}$ metal ions are represented in figure (3). These figures represent the results of removal efficiency of metal ions at different contact time from 10 minute to 90 minutes. As shown in the table the maximum removal occurs at 30 minute, where the removal efficiency of $\mathrm{Cd}$ from $44 \%$ to $48.8 \%, \mathrm{~Pb}$ from $13 \%$ to $37.9 \%$, Ni the removal efficiency between $40.8 \%$ and $62.8 \%$ and $\mathrm{Zn}$ removal efficiency between $45 \%$ to $49.4 \%$. The results show also that Ni has maximum efficiency $62.8 \%$ at 90 minute.

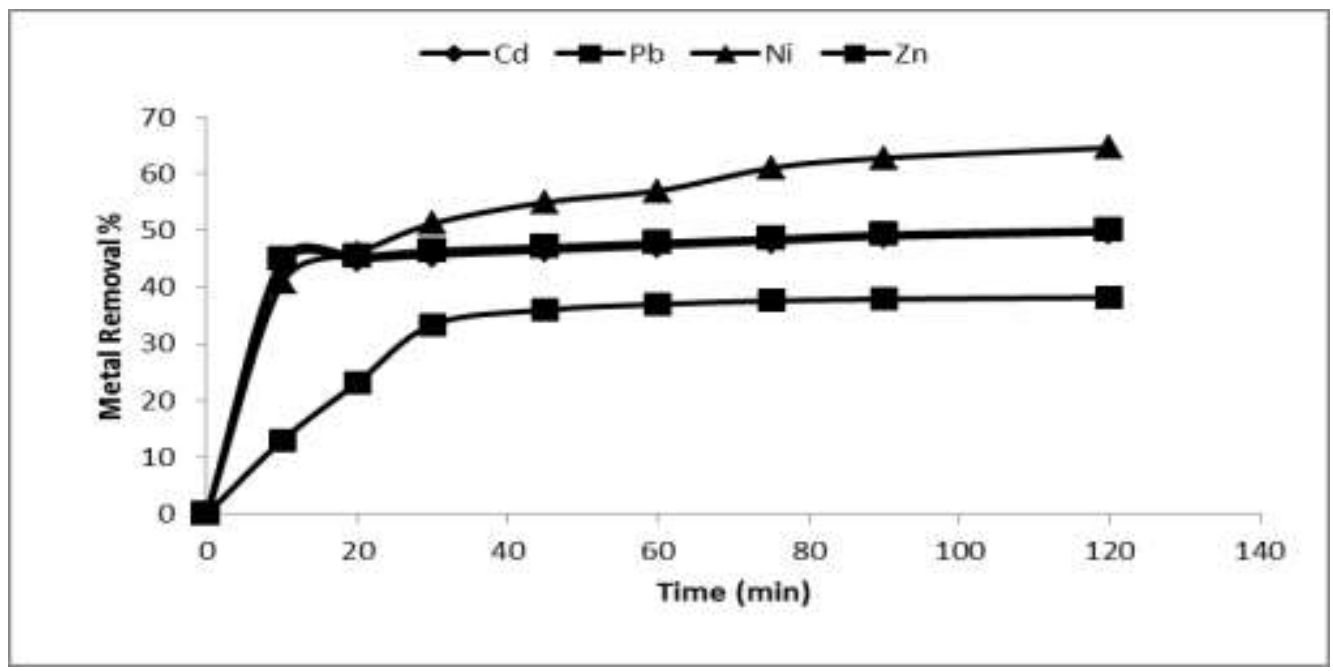

Fig. (3): The effect of contact time with adsorbent on the removal efficiency of $\mathrm{Cd}, \mathrm{Pb}, \mathrm{Ni}$ and $\mathrm{Zn}$ metal ions.

For metals ions removal efficiency and adsorption capacity are progressively increased with time and equilibrium was achieved after 90 minutes with range 39-64\% for metals ions. There is no critical increase in removal efficiency after $120 \mathrm{~min}$. 
J. Environ. Sci.

Institute of Environmental Studies and Research - Ain Shams University

\section{The results of removal efficiency of metal ions at different concentrations}

of: are illustrated by Fig. 4. It is evident that the capacity removal $(\mathrm{mg} / \mathrm{g})$ of metals ions increased with increasing initial concentration from $50 \mathrm{mg} / \mathrm{L}$ to $200 \mathrm{mg} / \mathrm{L}$. It is obvious that the capacity removal increases with increasing of initial metal ion concentration. This may be originated from increase of driving force of metals ions to active surface sites biochar surface.

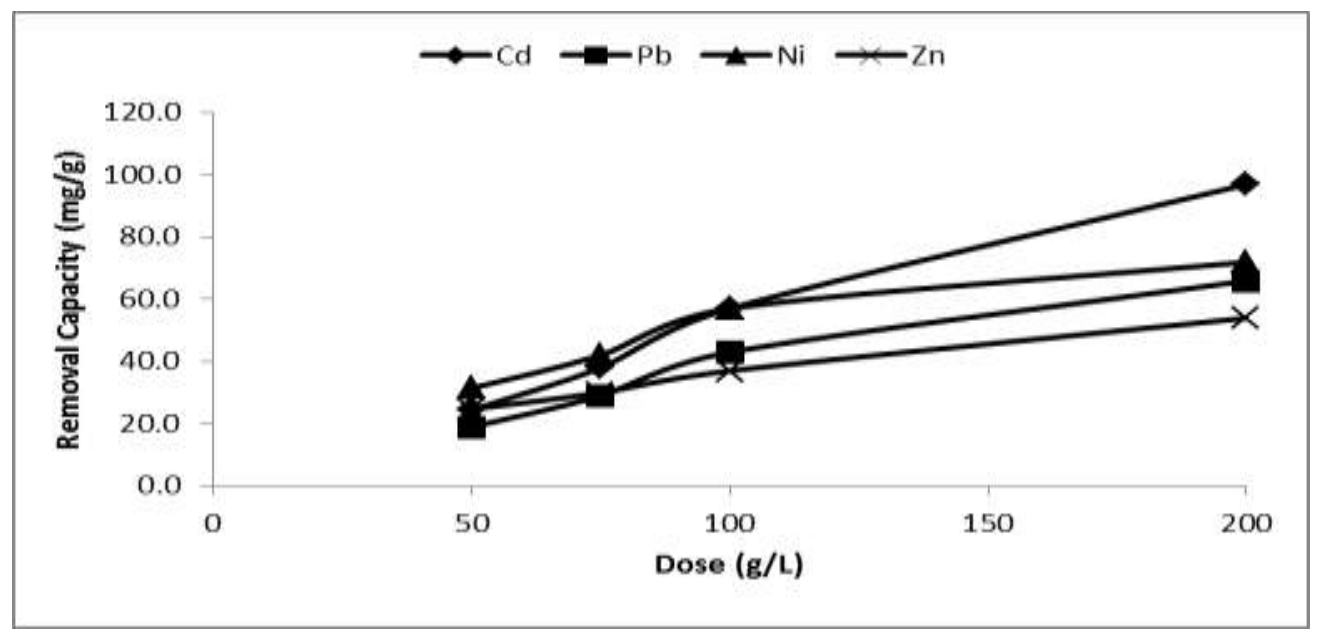

Fig. (4): Effect of initial metal ion concentration on the removal capacity of biochar for metals ions

\section{CONCLUSION}

Biochar was plausibly prepared from low cost agricultural waste (corncob), and it was used for decontamination of water from metals ions; $\mathrm{Cd}, \mathrm{Ni}, \mathrm{Pb}$, and $\mathrm{Zn}$ via adsorption process. The removal of $\mathrm{Cd}, \mathrm{Ni}, \mathrm{Pb}$, and $\mathrm{Zn}$ ions via adsorption from wastewater by biochar is studied under different conditions. Dose of $2 \mathrm{~g} / \mathrm{L}$ is chosen as optimal amount for metals adsorption. For metals ions, maximum removal reached to 38 to $63 \%$ after 90 minutes at 
$\mathrm{pH} 6.5$, dose of biochar of $2 \mathrm{~g} / \mathrm{L}$. It was noticeable that capacity removal increases with increasing of initial metal ion concentration. The results of present study indicate that easy and simple pretreatment of the inexpensive bio-sorbent consist of maize cob biomass show high-sorption performance of metal ions and feasibility of desorption and recovery sorption capacity.

\section{REFERENCES}

Ahmad, M.; Rajapaksha, A.U.; Lim, J.E.; Zhang, M.; Bolan, N.; Mohan, D., Vithanage, M.; Lee, S.S., and Ok, Y.S. (2014): Biochar as a sorbent for contaminant management in soil and water: a review. Chemosphere 99, 19-33.

Barakat, M.A. (2011): New trends in removing heavy metals from industrial wastewater. Arab. J. Chem. 4 (4), 361-377.

Demirbas, A. (2008): Heavy metal adsorption onto agro-based waste materials: a review. J. Hazard. Mater. 157 (2-3), 220-229.

Fu, F.L.; and Wang, Q. (2011): Removal of heavy metal ions from wastewaters: a review. J. Environ. Manage. 92 (3), 407-418.

Hu, X.; Ding, Z.H.; Zimmerman, A.R.; Wang, S.S.; and Gao, B. (2015): Batch and column sorption of arsenic onto iron-impregnated biochar synthesized through hydrolysis. Water Res. 68, 206-216.

Inyang, M.; Gao, B.; Yao, Y.; Xue, Y.W.; Zimmerman, A.R.; Pullammanappallil, P.; Cao, X.D. (2012): Removal of heavy metals from aqueous solution by biochars derived from anaerobically digested biomass. Bioresour. Technol. 110, 50-56.

Kumar, R.; Rani, M.; Gupta, H.; and Gupta, B.(2014): Trace metal fractionation in water and sediments of an urban river stretch. Chem. Speciation Bioavailability 26 (4), 200-209.

Mohan, D.; Sarswat, A.; Ok, Y.S.; and Pittman, C.U. (2014): Organic and inorganic contaminants removal from water with biochar, a 
renewable, low cost and sustainable adsorbent - a critical review. Bioresour. Technol. 160, 191-202.

Wang, S.S.; Gao, B.; Zimmerman, A.R.; Li, Y.C.; Ma, L.; Harris, W.G.; Migliaccio, K.W.(2015): Removal of arsenic by magnetic biochar prepared from pinewood and natural hematite. Bioresour. Technol. 175, 391-395.

Yao, Y.; Gao, B.; Chen, H.; Jiang, L.; Inyang, M.; Zimmerman, A.R.; Cao, X.; Yang, L.; Xue,Y.; and Li, H.(2012): Adsorption of sulfamethoxazole on biochar and its impact on reclaimed water irrigation. J. Hazard. Mater. 209, 408-413.

Zhou, Y.M.; Gao, B.; Zimmerman, A.R.; Chen, H.; Zhang, M.; and Cao, X.D. (2014): Biochar supported zerovalent iron for removal of various contaminants from aqueous solutions. Bioresour. Technol. 152, $538-542$.

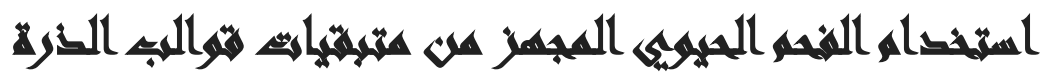

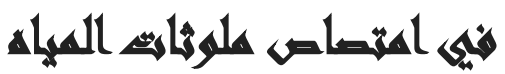

[1]

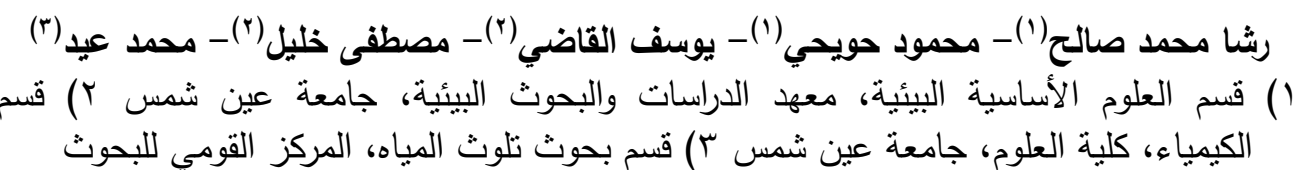

\section{(ill}

تم استخدام متبقيات قوالح الذرة في هذا العمل باعنباره مادة صلبة ممتزة لإزالة أيونات المعادن

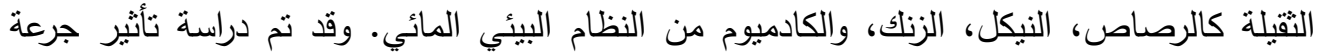

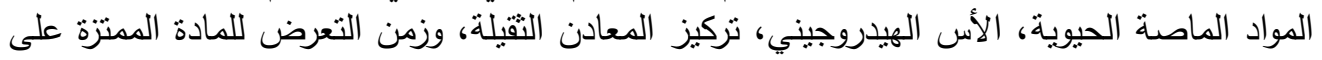

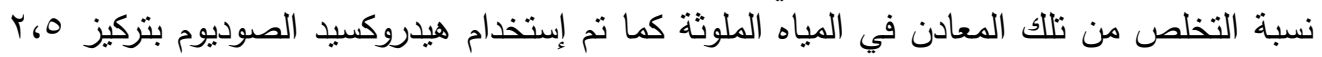

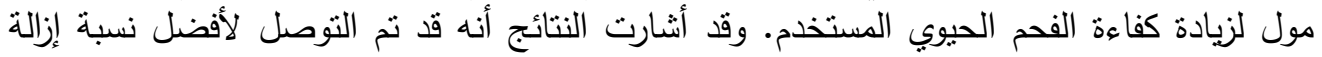

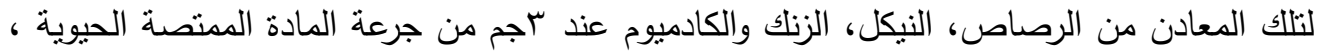

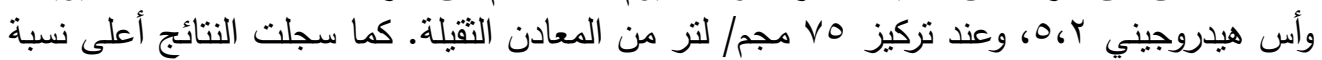

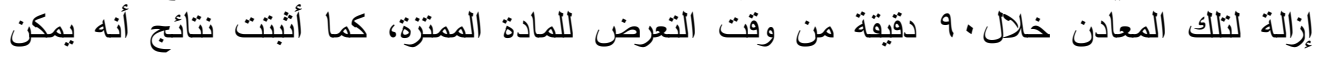


استخدام متبقيات قوالب الذرة بشكل مفيد في معالجة النظام البيئي المائي المحتوي على أيونات من

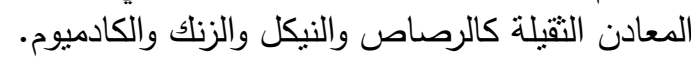
الكلمات الدالة: الأهتزاز ـ الفحم النباتي. ملوثات المياه. الإمتزاز الحيوي 